\title{
DEVELOPMENT OF A PORTABLE PNEUMATIC GRAIN BROADCASTING UNIT
}

\author{
Mokhtar C. Ahmad*
}

ABSTRACT

The present research was carried out in El-Sharkia Governorate, ElSowa Village in 2014 season to develop and evaluate a portable pneumatic grain broadcasting unit under Egyptian conditions in clay soil. The study included three fan peripheral speeds of 1.7, 1.97 and $2.18 \mathrm{~m} / \mathrm{s}$ with three grain path lengths of 50, 100 and $200 \mathrm{~mm}$ from air outlet under two types of dry and germinated grains. These parameters were evaluated with horizontal and vertical fan comparing to manual broadcasting on rice grains (Giza 178). Broadcasting width, coefficient of variance (CV), coefficient of distribution uniformity, consumed energy according to power requirements and total costs were determined under split-split plot design with three replicates for all treatments. The obtained results showed that fan peripheral speed of $2.18 \mathrm{~m} / \mathrm{s}$ and outlet path length of $100 \mathrm{~mm}$ with horizontal fan gave the best results for all tests. The highest broadcasting widths of 10.2 and $8.8 \mathrm{~m}$ were obtained under horizontal fan with dry and germinated grains, respectively. The least values for $C V$ were under fan peripheral speed of $2.18 \mathrm{~m} / \mathrm{s}$ and $100 \mathrm{~mm}$ outlet path length. $\quad C V$ values were 20.22, 18.25, 17.33 and 22.21, 21.15, 19.10 under fan peripheral speed of 1.7, 1.97 and $2.18 \mathrm{~m} / \mathrm{s}$ with $100 \mathrm{~mm}$ outlet path length for dry grains with horizontal and vertical fan positions, comparing to 47.50 for manual broadcasting. While the highest values of C.U. were 79.78, 81.75, 82.67 and 77.79, 78.85, 80.90 obtained at the same previous conditions. For germinated grains, CV values were 25.23, 21.12, 19.11 and 27.23, 25.15, 21.45 for horizontal and vertical fan, respectively comparing to 49.71 for manual broadcasting under the same fan peripheral speeds and outlet path length. The highest values of C.U. are 74.77, 78.88, 80.89 and 72.77, 74.85, 78.55 obtained at the same previous conditions. Consumed energy values were 0.56 and 0.87 $\mathrm{kWh} / f e d$, for dry and germinated grains, respectively. The broadcasting costs were 10.60 and 13.85 LE/fed for dry and germinated grains, respectively comparing to $20 \mathrm{LE} / f e d$ with the traditional method.

Key words: broadcasting, distribution, peripheral speed, air velocity

\footnotetext{
*Agric. Eng. Res. Inst., A. R. C., Egypt
} 


\section{INTRODUCTION}

The cultivated area of rice is about 1.363 million feddans that produced about 4.79 million tons' paddy rice. Because of

1 fragmented areas, most farmers use the manual method to broadcast grains in their fields, which give bad distribution uniformity. Mechanical rice planting is very important in saving hand labor, improving production, allowing further mechanization and decreasing production costs. Helmy et al. (2000) concluded that the grain yield of rice crop variety Giza 181, by using the mechanical drilling in dry condition, gave the lowest cost (87.5 L.E./Mg) and highest net profit (412.5 L.E./Mg). Kamel et al. (2002) indicated that there are significant differences in the amount skewing, coefficient of variation and minimum and maximum points in the overlapped pattern of resulting from choice of methods. Using blades with curved C-shaped, the coefficient of variation was varied from about 51.05 to $38.04 \%$ for spinner speed of $540 \mathrm{rpm}$ and -10 blade angle degrees without wind protection. Using spiral curved shaped blades; the coefficient of variation was varied from 42.70 to 32.93 $\%$ at the same conditions. Kishta and Eliwa (2005) developed and evaluated a portable grain and fertilizers spreader. They found that the highest uniformity coefficient of distribution of $95.80 \%$ is noticed at beater speed of $500 \mathrm{rpm}$ when using the electrical device in the wheat field. Increasing total required time $1.2 \mathrm{~h} /$ fed by manual device (fertilizer) caused to continuous decreasing in effective field capacity. The highest field efficiency of $61.60 \%$ and the lowest operational cost of $1.57 \mathrm{LE} / \mathrm{fed}$ are achieved at a better speed of $500 \mathrm{rpm}$ using electrical spreader in the wheat field. Morad et al. (2005) reported that the optimum distribution pattern and high degree of fertilizer uniformity can be achieved under the following conditions: Linear speed of about $10.5 \mathrm{~m} / \mathrm{s}$, (500 rpm), blade angle of $+15 \mathrm{deg}$ forward, $(0.26 \mathrm{rad})$, dip angle of $0 \mathrm{deg}(0 \mathrm{rad})$, gate opening of $16.63 \mathrm{~cm}^{2}$ and machine forward speed of about $6 \mathrm{~km} / \mathrm{h}$. Abo El-Naga (2006) found that the best uniformity of grain distribution obtained by using developed distributor unit at diameter of pipe $5.08 \mathrm{~cm}$ and air stream velocities of 12.5 and $17.75 \mathrm{~m} / \mathrm{s}$. Best uniformity of grain distribution obtained by using developed distributor at pipe diameter of $3.81 \mathrm{~cm}$ and air stream velocities of 12.5 and $17.75 \mathrm{~m} / \mathrm{s}$. Increasing of air 
stream velocity increased grain discharge for all varieties of small grains at steady gate out area $4.28 \mathrm{~cm}^{2}$. Khoshtaghaza and Mehdizadeh (2006) showed that by increasing mass of the kernel from 0.02 to $0.05 \mathrm{~g}$ and moisture content from 7 to $20 \%$ (w.b.), its terminal velocity increased linearly from 7.04 to $7.74 \mathrm{~m} / \mathrm{s}$ and 6.81 to $8.63 \mathrm{~m} / \mathrm{s}$, respectively. Alireza and Sheikhdavoodi (2012) stated that the uniformity and accuracy of seed broadcasting on field surface is significant parameter of broadcaster performance and improper and inaccurate broadcasting causes abnormal and nonhomogeneous soil fertility which is against to the purposes of sustainable agriculture. Also, broadcasters are used for planting seeds like wheat, barley etc., so it's appropriate performance effect on crop production.

Aerodynamic properties such as the terminal velocities of agricultural products are important and required for the design of air conveying systems and the separation equipment. Physical properties such as density, shape and size, etc. need to be known for calculating the terminal velocity and drag coefficient for separating the desirable products from unwanted materials. As a result, aerodynamic properties such as terminal velocity and drag coefficient are needed for air conveying and pneumatic separation of materials (Gupta et al., 2007). Gharekhani et al. (2013) mentioned that the terminal velocity of paddy and white rice increased linearly with an increase in moisture content from 5 to $37 \%$ (w.b.). The drag coefficient of white rice decreased linearly while for paddies the two varieties showed a quadratic trend with moisture content increase. Generally, the use of tractor with ordinary attached broadcasting machines could be compact the soil layers due to its heavy weight. Therefore, the object of this research is to manufacture and evaluate a broadcasting unit to give the best uniformity of grains distribution, the high field capacity and efficiency, save total cost requirements and also reduce soil compaction to the minimum values.

\section{MATERIALS AND METHODS}

Field experiments were carried out at private farm at El-Sowa Village, ElSharkia Governorate, to develop and evaluate a portable pneumatic grainbroadcasting unit during 2014 season. The experimental tests done in 
Soil Dept., Faculty of Agric., Zagazig University at clay soil texture. Soil specifications are presented in table 1.

Table 1: Soil physical analysis: -

\begin{tabular}{|c|c|c|c|c|}
\hline \multicolumn{4}{|c|}{ Soil composition\% } & \multirow{2}{*}{ Soil texture } \\
\hline Clay, \% & \multirow{2}{*}{ Silt, $\%$} & \multicolumn{2}{|c|}{ Sand, \% } & \\
\cline { 3 - 4 } & & Coarse & Fine & \\
\hline 48 & 20 & 5.2 & 26.8 & Clay \\
\hline
\end{tabular}

\section{Test factors:}

The used grains: The paddy grains, which were selected for this research, was a commercial variety of paddy grains, Giza 178 and were obtained from Al-Serw Agric. Res. Station, Agric. Res. Center, Egypt. The grains were cleaned manually to remove all foreign matters, broken and immature grains. The initial grain moisture content was determined using a pre-calibrated moisture meter (Wile 35). All the physical properties were assessed at the moisture content of $12.2 \%$ (wet basis).

To determine the angle of repose of the paddy grains, a plastic tube with $110 \mathrm{~mm}$ diameter and $120 \mathrm{~mm}$ height was kept vertically on a horizontal floor and filled with the sample from a height of $150 \mathrm{~mm}$. The tube was slowly raised over the glass floor so that whole material could slide and form a heap. The angle of repose was calculated using the following equation (Jha ,1999):

$$
\theta=\tan ^{-1}\left(\frac{2 H}{D}\right)
$$

Where, $\theta$ is the angle of repose in degrees, $\mathrm{H}$ and $\mathrm{D}$ are the height and diameter of the heap in $\mathrm{mm}$, respectively.

The modified paddy grain portable unit was evaluated for broadcasting 60 $\mathrm{kg} / \mathrm{fed}$ of dry and germinated paddy grains in clay soil after puddling process (leveling in water). The physical properties of the paddy grains are tabulated in Table (2).

Table (2): Physical properties of paddy grains

\begin{tabular}{|c|c|c|c|c|c|}
\hline $\begin{array}{c}\text { Grains } \\
\text { (paddy) } \\
\text { Form }\end{array}$ & $\begin{array}{c}\text { Bulk } \\
\text { density, } \\
\left(\mathbf{g} / \mathbf{c m}^{\mathbf{3}} \text { ) }\right.\end{array}$ & $\begin{array}{c}\text { Moisture } \\
\text { content, } \\
(\boldsymbol{\%})\end{array}$ & $\begin{array}{c}\text { Angle of } \\
\text { repose, } \\
\text { (deg.) }\end{array}$ & $\begin{array}{c}\text { Coefficient } \\
\text { of friction } \\
\text { with plastic }\end{array}$ & $\begin{array}{c}\text { Diameter } \\
\text { range, } \\
(\mathbf{m m}\end{array}$ \\
\hline Dry & 0.545 & 12.2 & $44 \pm 0.28$ & $0.54 \pm 0.41$ & $2-4 \pm 0.34$ \\
\hline Germinated & 0.684 & 19.5 & $52 \pm 0.28$ & $0.61 \pm 0.41$ & $2-4 \pm 0.34$ \\
\hline
\end{tabular}




\section{The developed portable unit construction}

Specifications of The developed portable unit Fig. 1 are shown in Table 3.

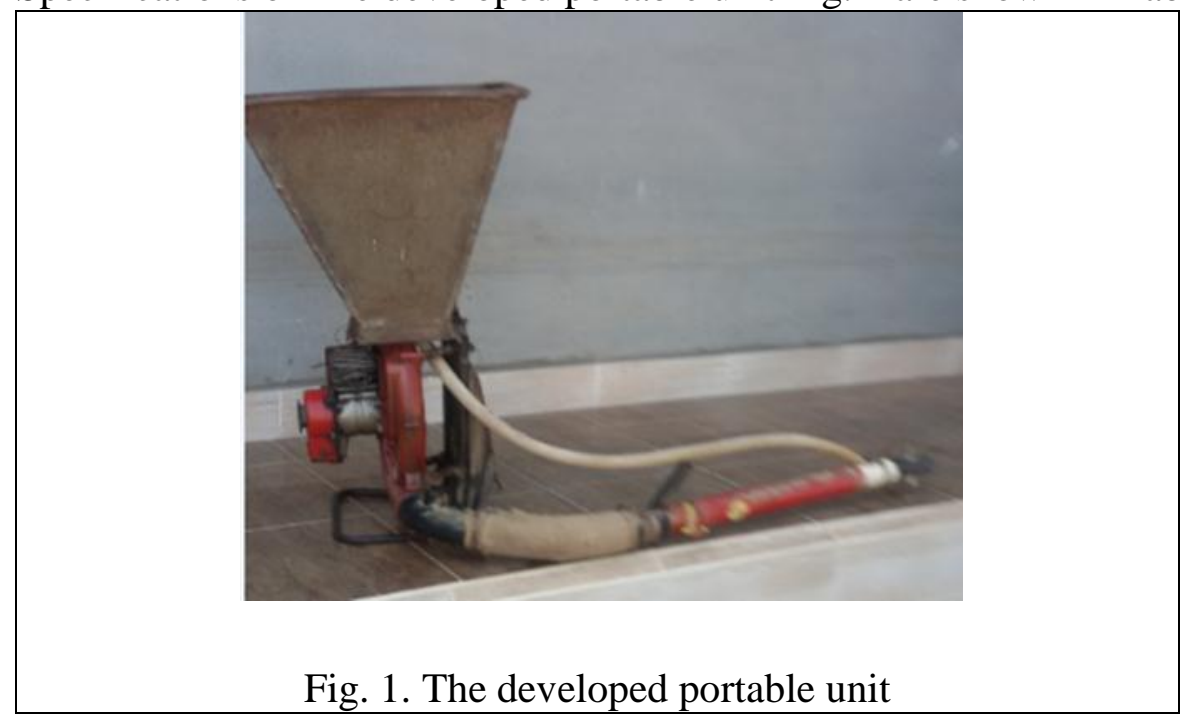

Table 3: Specifications of The developed portable unit

\begin{tabular}{|l|l|l|c|}
\hline \multicolumn{1}{|c|}{ Item } & \multicolumn{1}{|c|}{ Specifications } & \multicolumn{1}{c|}{ Item } & Specifications \\
\hline Engine & $\begin{array}{l}\text { strokes, air } \\
\text { cooling, } \\
\text { single cylinder, } \\
\text { gasoline }\end{array}$ & Air flow $\left(\mathrm{m}^{3} / \mathrm{h}\right)$ & 640 \\
\hline $\begin{array}{l}\text { Cylinder } \\
\text { Volume (cc) }\end{array}$ & 70 & $\begin{array}{l}\text { Air velocity } \\
(\mathrm{m} / \mathrm{sec} .)\end{array}$ & 100 \\
\hline $\begin{array}{l}\text { Rotation } \\
(\mathrm{rpm})\end{array}$ & 6000 & Fuel cons.(L/h) & 4.25 \\
\hline Power $(\mathrm{kW})$ & 3.68 & Fuel tank (L.) & 1.8 \\
\hline Mass net $(\mathrm{kg})$ & 15.5 & Tank capacity (L.) & 20 \\
\hline
\end{tabular}

The developed portable unit consists mainly of the grain hopper, broadcasting device and power system. The specifications of each part could be discussed as follows:

\section{Grain hopper}

The developed portable unit (Fig. 2) has a quadrilateral steel hopper (1), $0.5 \mathrm{~mm}$ thickness with dimensions of $600 \mathrm{~mm}$ height and $500 \mathrm{~mm}$ upper 
width with $100 \mathrm{~mm}$ bottom width at approximately volume of $0.062 \mathrm{~m}^{3}$. A $30 \mathrm{~mm}$ outlet diameter was adjusted for rice grain flow. At the bottom outlet of the hopper there is an outlet grain gate with area of $5.069 \mathrm{~cm}^{2}$ (2); controlled by the outlet grain controller (5), and a plastic grain hose (6) of about $30 \mathrm{~mm}$ diameter and $500 \mathrm{~mm}$ length.

The grain hose is connected to the end of the air duct tube (4) at individually three different holes of 50,100 and $200 \mathrm{~mm}$ to be tested under treatments as the outlet path length [the point where air duct and grains are facing before leaving the tube end and hit the spreader fan (8)].
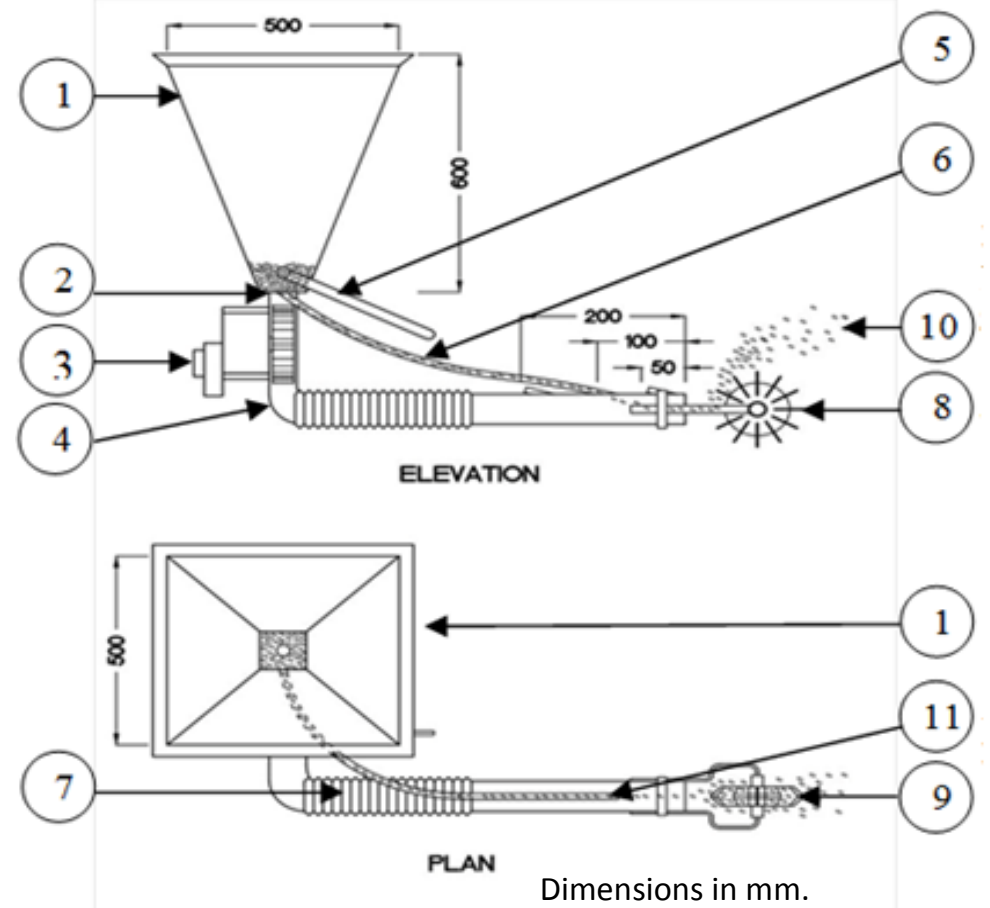

1- Hopper; 2- Grain gate; 3- Engine and pump; 4- Air duct tube; 5- Gate control;

6- Grain tube; 7- Flexible hose; 8- Spreader fan (horizontal position)

9- Spreader fan;10- Broadcasting grains; 11- Grain inlet hole

Fig. 2: A schematic diagram of The developed portable unit

\section{Broadcasting device}

The developed unit has a plastic spreader fan (Fig. 3) with maximum diameter of $130 \mathrm{~mm}$ and maximum height of $40 \mathrm{~mm}$ with 12 vertical hexagonal vanes. Each vane is $40 \mathrm{~mm}$ height; $40 \mathrm{~mm}$ width with $1.0 \mathrm{~mm}$ thickness. The vanes angle was adjusted at zero deg. according to (Morad 
et al. 2005). The broadcasting device is rotating depending on the air ducted from the engine pump through the air duct tube.

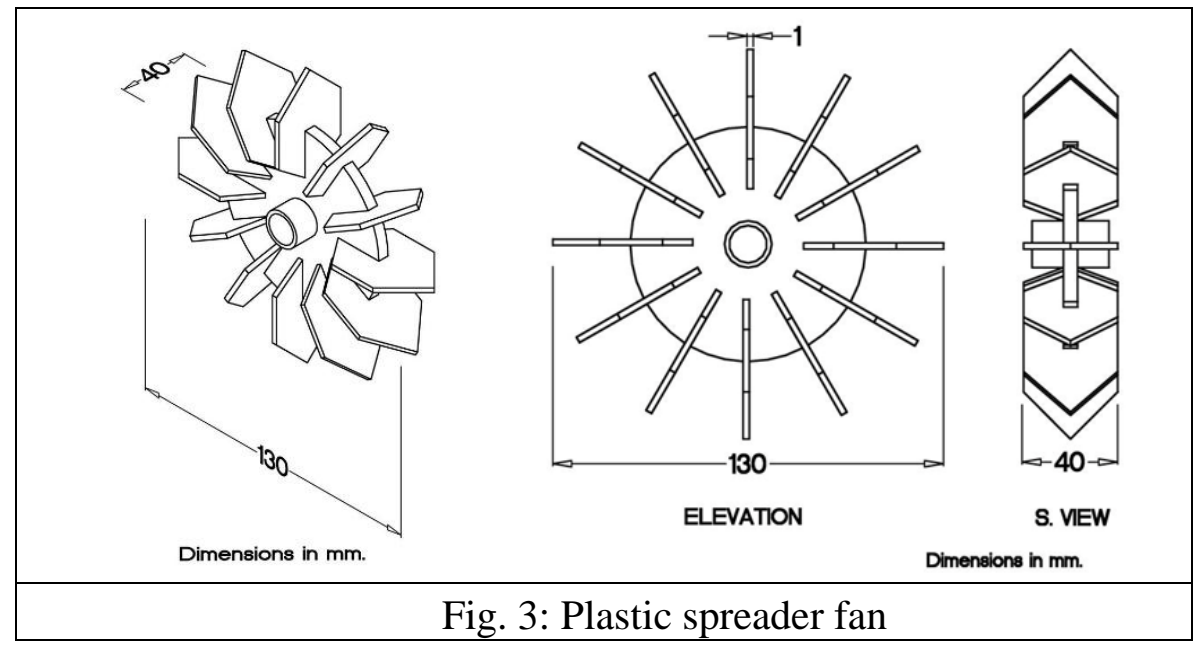

\section{Power system}

As in Fig. 3, The engine (3) of about 3. $68 \mathrm{~kW}$ transmits the power to an inertial aluminum pump which blasts air that broadcasting grains through blowing air.

Test factors: The study included;

- three spreader fan rotational speeds of 250, 290 and $320 \mathrm{rpm}$ represents fan peripheral speeds of $1.7 \mathrm{~m} / \mathrm{s}, 1.97$ and $2.18 \mathrm{~m} / \mathrm{s}$, respectively according to three air velocities of 50,75 and $90 \mathrm{~m} / \mathrm{s}$, respectively.

- three grain path lengths of 50,100 and $200 \mathrm{~mm}$ from air outlet were pinpointed by making three circular holes on the air duct tube before the end of the grain outlet path. Two of the three holes must be closed while using the third one in each treatment to prevent air leakage.

- two grain states (dry and germinated) in dry and muddy soil, respectively.

- two spreader fan positions of horizontal and vertical comparing to the manual broadcasting.

- Field trials were carried out to estimate the operator speed (ground speed) and was supposed to be steady at $2.4 \mathrm{~km} / \mathrm{h}(0.67 \mathrm{~m} / \mathrm{s})$ according to operator motion in mud.

Note: It is advisable to pay attention that, this measurement was carried out depending on steady-hand operator (without moving from left to right 
and without twisting) to pinpoint the broadcasting centerline and measure the broadcasting width accurately depending only on spreader fan distribution. Also, field capacity was estimated according to time consumed and also timed consumed as re-filling the hopper with grains three times/fed with dry grains and four times with germinated grains.

\section{INSTRUMENTATION}

- Speedometer: Speedometer laser technique was used for measuring the broadcasting fan.

- Graduated flask: One liter graduated flask with accuracy of $0.01 \mathrm{~cm}^{3}$ was used to measure grains bulk density.

- Moisture content caliper: A Wile 35 Moisture meter was used for measuring grains moisture content (wet basis) before broadcasting grains.

- Electronic balance: An electronic balance was used for weighing grains while filling grain hopper before broadcasting grains with accuracy of $0.5 \mathrm{~g}$.

- Wooden frame: A square wooden frame of $1.0 \mathrm{~m}^{2}$ with $50 \mathrm{~mm}$ height was constructed. The frame bottom was covered by a plastic sheet for gathering the broadcasted grains during laboratory tests.

During all experiments, the average wind speed was about $2.1 \mathrm{~km} / \mathrm{h}(0.69$ $\mathrm{m} / \mathrm{s}$ ) and the air temperature varied from 22 to $28{ }^{\circ} \mathrm{C}$. After each treatment, the materials from each sheet was put in small sacs and weighted to calculate the coefficient of variation and coefficient of uniformity. Accordingly, grain germination and damage were tested in vitro and were found to be neglected as there was no effect while using the modified grains portable unit.

\section{Experimental Procedures}

In split-split plot design, an experimental area of about 2.0 feddans were divided into two main plots represent the grain status (dry and germinated grains) and each of them was divided into three sup plots according to the used broadcasting system (horizontal or vertical spreader fan position and manual broadcasting). Two of sup plots were divided into three sup-sup plots according to spreader fan peripheral speeds. The experimental treatments were carried out after the soil tillage and irrigation then 
puddling (leveling in water) and were replicated three times. The outlet grain gate was adjusted for the two broadcasting systems at $60 \mathrm{~kg} / \mathrm{fed}$.

\section{MEASUREMENTS}

\section{A - Broadcasting width}

The distribution uniformity pattern (includes the coefficient of variation and coefficient of uniformity) indicates the degree of grains uniformity distribution in terms of coefficient of variation and symmetry.

To evaluate of the distribution pattern and unit performance was carried out using collection sheets having dimensions of $1.0 \times 1.0 \mathrm{~m}$.

\section{- Coefficient of Variation (CV)}

According to Coates (1992), the standard deviation $(\delta)$ and coefficient of variation $(\mathrm{CV})$ are determined as follows:

$$
\delta=\sqrt{\frac{\sum\left(x_{i}-x_{a}\right)^{2}}{n-1}}
$$

Where:

$x_{i}=$ The individual reading.

$x_{a}=$ Mean reading $=\sum \frac{x_{i}}{n}$

$n=$ Number of readings.

$$
C . V .=\frac{\delta}{x_{a}} x 100
$$

\section{- Coefficient of uniformity (CU)}

The coefficient of distribution uniformity is calculated by the following equation, (Dragos, 1975):

$$
\text { C.U. }=1-C V \text {. }
$$

\section{B- Energy requirements}

The following formula was used to estimate power consumption (Hunt, 1983):

$$
P=\frac{F C \times \rho . f \times L C V \times 427 \times \eta_{\text {th }} \times \eta_{\text {mec }}}{3600 \times 75 \times 1.36} k W
$$

Where:

$\mathrm{FC}=$ fuel consumption, $\mathrm{L} / \mathrm{h}$, 
$\rho . \mathrm{f}=$ density of fuel, $\mathrm{kg} / \mathrm{L}$ (for diesel $=0.85$ ),

L.C.V= calorific value of fuel $(10000 \mathrm{kcal} / \mathrm{kg})$,

$427=$ thermo-mechanical equivalent, $\mathrm{J} / \mathrm{kcal}$,

$\eta_{t h}=$ thermal efficiency of engine $(\approx 35 \%$ for diesel engines $)$ and

$\eta_{\text {mec }}=$ mechanical efficiency of engine $(\approx 80 \%)$.

The specific energy calculated by using the following equation

Specific energy $(k W . h / f e d)=\frac{\text { Power requirement }(k W)}{\text { Effective field capacity }(\text { fed } / h)} .$.

\section{D- Broadcasting cost.}

The economic machinery costs (fixed and variable) as well as repair and maintenance is derived from theories described by Nilsson (1972), Have (1991) and Hunt (1995), and expresses the total yearly fixed and variable costs as a function of machine capacity:

$C=\left[\psi \times \rho \times \theta+\frac{A x U}{\theta \times F E} x(r \times \rho \times \theta+L+\delta x \theta)\right] / \operatorname{Pr}$

Where; $\mathrm{C}$ : is the total yearly costs (LE),

$\Psi$ : is a factor expressing depreciation and interest as a fraction of the purchase price, (1/year)

$\rho$ : is the purchase price per unit capacity (LE.h/ton),

$\theta$ : is the machine capacity (ton/h),

$A$ : is the treated seasonal area (fed/year),

$U:$ is the expected crop yield (ton/fed),

$F E$ : is the field efficiency expressing the ratio between gross and theoretical capacity,

$r$ : is a factor expressing repair and maintenance costs as a fraction of purchase price,

$\delta$ : is the fuel costs proportional to the capacity ( $\mathrm{LE} / \mathrm{L})$, and

Pr: is process productivity (ton).

- Statistical analysis: The obtained data were tabulated and analyzed statistically by using a computer program for estimating the regression analysis and the probability at level $5 \%$ while the graphs were drawn using the Microsoft excel window 2007. 


\section{RESULTS AND DISCUSSION}

\section{A- Effect of spreader fan peripheral speed on broadcasting width}

From Fig 4, it is indicated that increasing fan peripheral speed resulted in increasing broadcasting width. For dry grains, results in Fig. 4 (A) show that the most amount of grains is distributed in small width at lower fan peripheral speed of $1.7 \mathrm{~m} / \mathrm{s}$ compared with the high speed of 1.97 and $2.18 \mathrm{~m} / \mathrm{s}$ which increases the broadcasting width around the centerline of the portable unit carrier especially under $200 \mathrm{~mm}$ outlet path length.

The broadcasting width readings were 10.2, 6.4 and $4.4 \mathrm{~m}$ under fan peripheral speed of $2.18 \mathrm{~m} / \mathrm{s}$ and outlet path length of $200 \mathrm{~mm}$ for horizontal and vertical fan comparing to manual broadcasting, respectively. It is clear that fan peripheral speed of $2.18 \mathrm{~m} / \mathrm{s}$ and outlet path length of $200 \mathrm{~mm}$ showed the best broadcasting width. Fan peripheral speed of $1.7 \mathrm{~m} / \mathrm{s}$ with outlet path length of $50 \mathrm{~mm}$ showed the least values of broadcasting width while fan peripheral speed of $1.97 \mathrm{~m} / \mathrm{s}$ and outlet path length of $100 \mathrm{~mm}$ showed medium values and the two factors gave similar trends.

For germinated grains, similar trends were shown in Fig. 4 (B). Under the same previous conditions of fan peripheral speed and outlet path length values of broadcasting widths were $8.8,5.5$ and $3.7 \mathrm{~m}$ for horizontal and vertical fan comparing to manual broadcasting, respectively. These results were under fan peripheral speed of $2.18 \mathrm{~m} / \mathrm{s}$ and $200 \mathrm{~mm}$ outlet path length. In the same way fan peripheral speed of $1.7 \mathrm{~m} / \mathrm{s}$ and outlet path length $50 \mathrm{~mm}$ showed the least values of broadcasting width and medium values were obtained under fan peripheral speed of $1.97 \mathrm{~m} / \mathrm{s}$ with two other outlet path length of 50 and $100 \mathrm{~mm}$. This result may be attributed to the increase in centrifugal force occurred by high fan peripheral speed which caused increasing fan speed. So, the effective width could be increased by increasing fan peripheral speed. Comparing the two states of grains there were significant differences between dry and germinated grains $\left(\mathrm{R}^{2}=0.9494\right)$.

\section{Effect of fan peripheral speed and outlet path length on CV and CU.}

Fig 5 shows the effect of fan peripheral speed and outlet path length on $\mathrm{CV}$ for both dry and germinated grains at different positions of fan comparing to manual broadcasting. 

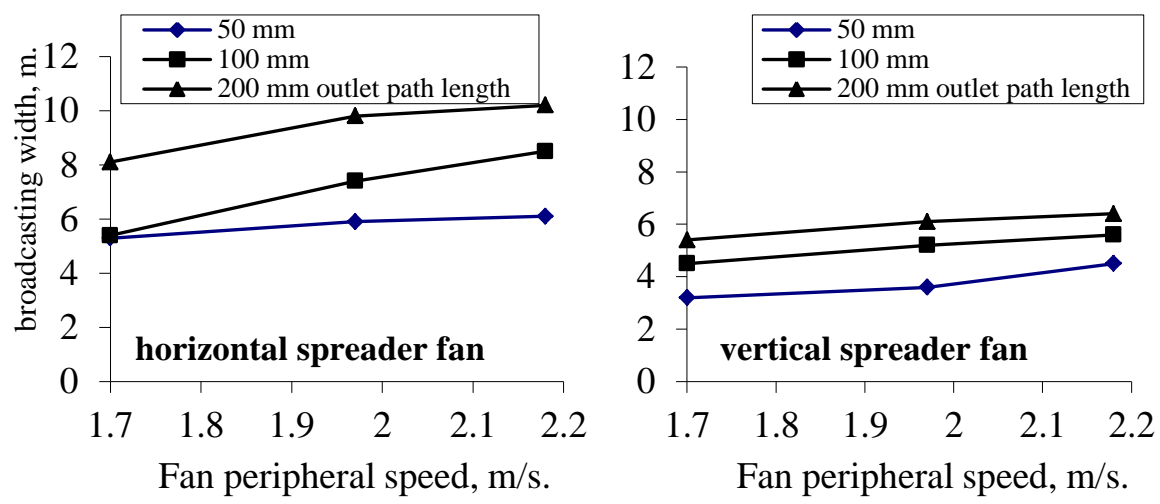

(A) Dry grains
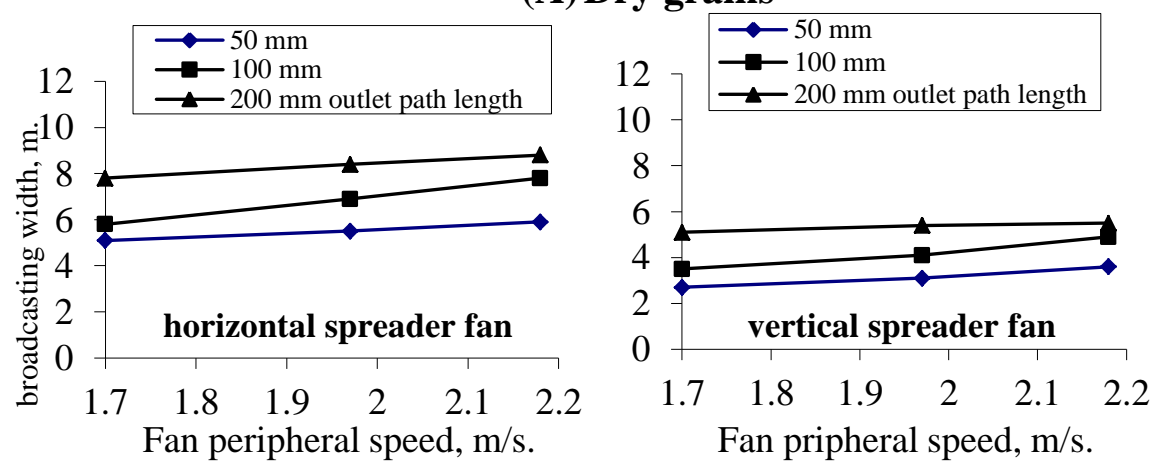

(B) Germinated grains

Fig.4: Effect of fan peripheral speed and outlet path on broadcasting width for (A): dry grains and (B) germinated grains

For dry grains from Fig 5 (A), it is clear that increasing fan peripheral speed resulted in decreasing $\mathrm{CV}$ values under all treatments and consequently increasing the CU. Also, it is obvious that using fan showed a decrement in $\mathrm{CV}$ values comparing with the control treatment. Using horizontal fan gave the least values for CV in all treatments. CV values were $20.22,18.25,17.33$ and 22.21, 21.15, 19.10 for horizontal and vertical fan, respectively comparing to 47.50 for control treatment (manual broadcasting). These results were under fan peripheral speed of $1.7,1.97$ and $2.18 \mathrm{~m} / \mathrm{s}$ with $100 \mathrm{~mm}$ outlet path length. The highest values of C.U. are $79.78,81.75,82.67$ and $77.79,78.85,80.90$ obtained at the same previous conditions. These results may be attributed to the increase in centrifugal force occurred at high peripheral speed. So, the coefficient of variation could be decreased by increase fan peripheral speed. The best 
distribution pattern is coincided the lowest values of C.V. The fan peripheral speed of 2.18 gave the lowest value of C.V. of 22.71, 17.33, 20.19 and 27.11, 19.01, 23.11 under different outlet path length of 50, 100 and $200 \mathrm{~mm}$ for horizontal and vertical position, respectively. Results show that, the suitable peripheral speed for dry grains is $2.18 \mathrm{~m} / \mathrm{s}$. The two other outlet path length showed similar results and trends.

With germinated grains Fig 5 (B), the same trend for CV values were shown for all treatments comparing to the control treatments under the same conditions with dry grains. CV values were 25.23, 21.12, 19.11 and $27.23,25.15,21.45$ for horizontal and vertical fan, respectively comparing to 49.71 for control treatment (manual broadcasting). These results were under fan peripheral speed of $1.7,1.97$ and $2.18 \mathrm{~m} / \mathrm{s}$ with 100 $\mathrm{mm}$ outlet path length. The highest values of C.U. are 74.77, 78.88, 80.89 and $72.77,74.85,78.55$ obtained at the same previous conditions. These results may be attributed to the increase in centrifugal force occurred at high peripheral speed.

Although the outlet path length of $50 \mathrm{~mm}$ showed the best broadcasting cone, but the number of grains per $\mathrm{m}^{2}$ was less than the recommended values. Therefore, outlet path length of $100 \mathrm{~mm}$ showed the best values of number of grains per $\mathrm{m}^{2}$. The regression analysis showed that outlet path length is an important factor which affects the coefficient of variations of broadcasting $\left(\mathrm{R}^{2}=0.957\right)$. It was found that, with the probability of $5 \%$ which meant outlet path length value affects coefficient of variations of broadcasting. The maximum coefficient of variations was gained for manual broadcasting and the minimum value was obtained in broadcasting grains by horizontal and vertical fan broadcasting. These results may be because more fan peripheral speed results in more grains distribution and in the same way the outlet path length of 50 and $200 \mathrm{~m}$ led to sudden impact for grains with scattering fan with $50 \mathrm{~mm}$ and more friction with $200 \mathrm{~mm}$ which showed the obtained results.

\section{Effect of fan peripheral speed on specific energy:}

Specific energy is highly affected by fan peripheral speed. Fig.6 shows that increasing fan peripheral speed from 1.7 to $2.18 \mathrm{~m} / \mathrm{s}$ decreased specific energy from 1.12 to $0.45 \mathrm{kWh} / \mathrm{fed}$, for dry and germinated grains, respectively. 

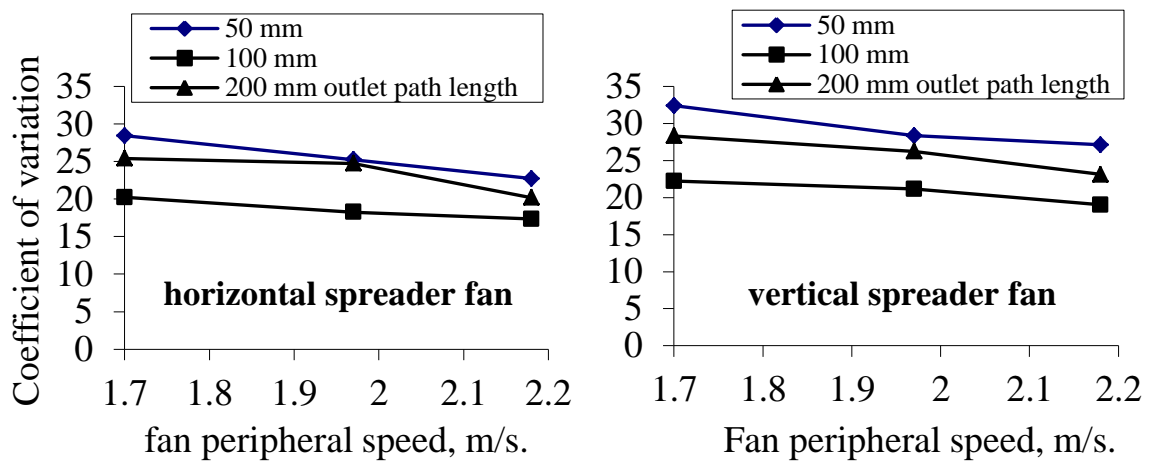

(A) Dry grains

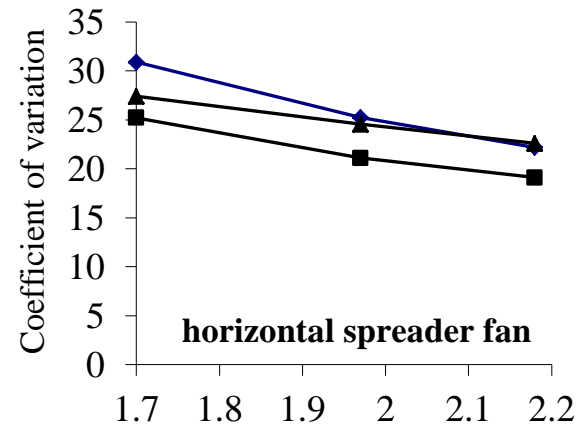

Fan peripheral speed, $\mathrm{m} / \mathrm{s}$.

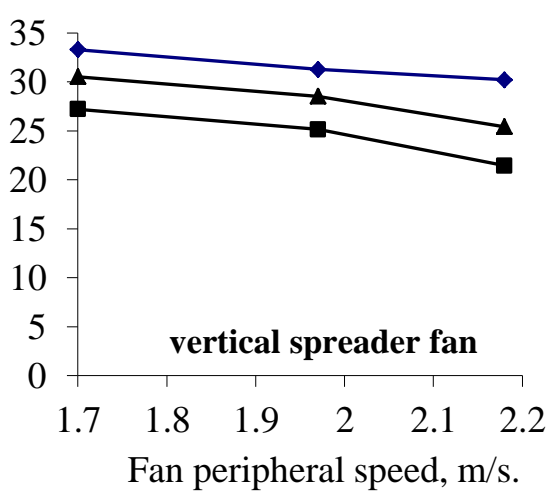

(B) Germinated grains

Fig.5: Effect of fan peripheral speed and outlet path on coefficient of variation for: (A) dry grains and (B) germinated grains

The decrease of specific energy consumed as the fan peripheral speed increased was attributed to change portable unit fuel consuming to the high velocity and also the increase in portable unit field capacity. The specific energy values at the suitable portable unit fan peripheral speed of $2.18 \mathrm{~m} / \mathrm{s}$ were 0.56 and $0.87 \mathrm{kWh} / \mathrm{fed}$, for dry and germinated grains, respectively. These values of energy consumed are considered economically so cheap comparing with the manual broadcasting specially in mud as there is no other equipment could broadcast grains in mud and therefore, in Egypt, grain broadcasting is widely manually operated. 

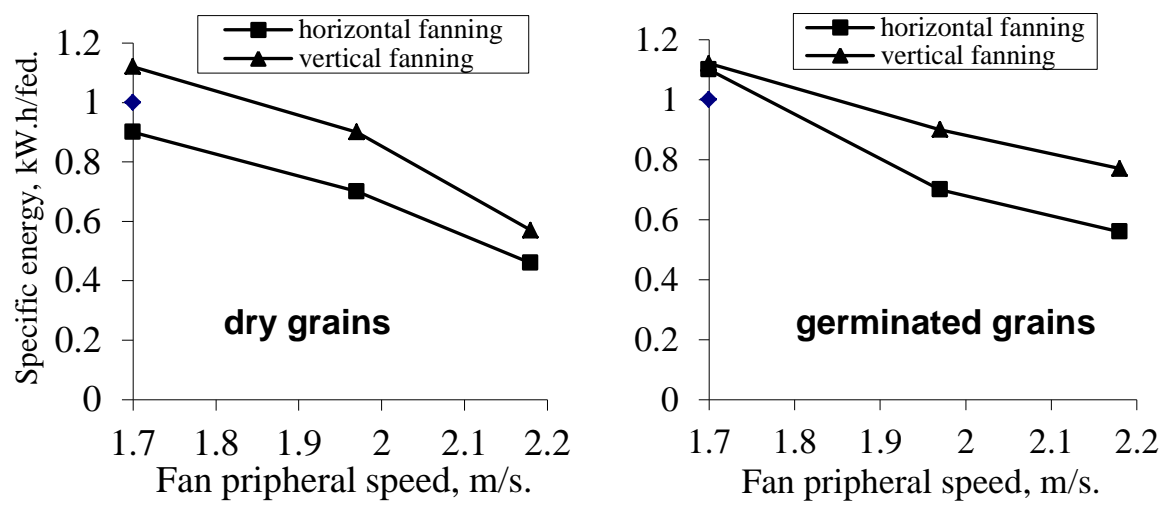

Fig.6: Effect of fan peripheral speed and outlet path length on specific energy under $100 \mathrm{~mm}$ outlet path length with dry and germinated grains

\section{Effect of different parameters on broadcasting cost:}

Although the outlet path length of $200 \mathrm{~mm}$ (Fig 7) showed the highest broadcasting width, the outlet path length of $100 \mathrm{~mm}$ showed the least values of $\mathrm{CV}$ concerning the effect of ground speed on broadcasting cost (LE/fed). Data indicated that at the mentioned ground speeds of $0.67 \mathrm{~m} / \mathrm{s}$ with fan peripheral speed of $2.18 \mathrm{~m} / \mathrm{s}$ and outlet path length of $200 \mathrm{~mm}$ the average broadcasting costs were 10.60 and $13.85 \mathrm{LE} / \mathrm{fed}$ for dry and germinated grains, respectively comparing to $20 \mathrm{LE} / \mathrm{fed}$ for manual broadcasting according to the operator rental costs per hour.

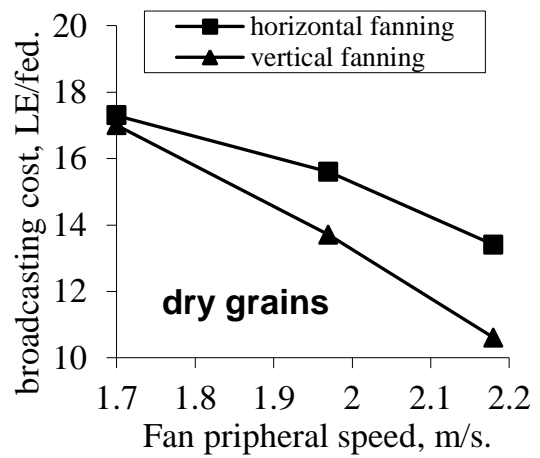

Fig.7: Effect of fan peripheral speed and outlet path length on broadcasting cost under $200 \mathrm{~mm}$ outlet path length with dry and germinated grains

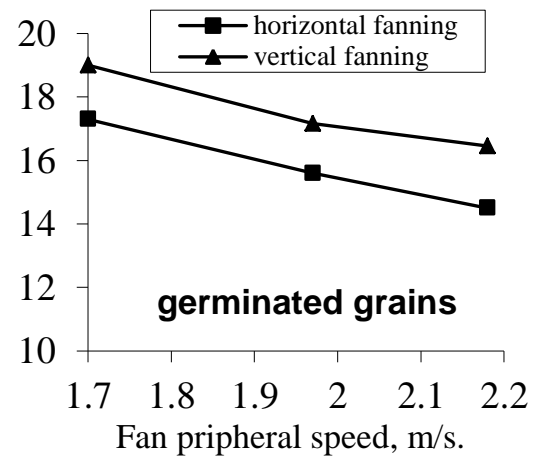

Fan pripheral speed, $\mathrm{m} / \mathrm{s}$. 
These mentioned results were estimated according to time consumed and also timed consumed while re-filling the hopper with grains three times/fed with dry grains and four times with germinated grains assuming broadcasting width of approximately $10 \mathrm{~m}$. It is noticed that increasing fan peripheral speed resulted in decreasing broadcasting cost. This was attributed to the increase in portable unit field capacity and they were considered to be acceptable compared with manual broadcasting.

\section{CONCLUSION}

It was found that the developed portable unit is suitable for paddy grains broadcasting effectively with dry or germinated grains and it is so easy to be manufactured and adjusted to be used for different agricultural operations. The desirable results could be summarized as follows:

- The highest broadcasting width of 10.2 and $8.8 \mathrm{~m}$ was obtained under fan peripheral speed of $2.18 \mathrm{~m} / \mathrm{s}$ and outlet path length of $200 \mathrm{~mm}$ for horizontal fan of dry and germinated grains, respectively.

- For dry grains Under fan peripheral speed of 1.7, 1.97 and $2.18 \mathrm{~m} / \mathrm{s}$ and $100 \mathrm{~mm}$ outlet path length gave the least CV values of 20.22, $18.25,17.33$ and $22.21,21.15,19.10$ for horizontal and vertical fan, respectively comparing to 47.50 for control treatment (manual broadcasting ), the highest values of C.U. are 79.78, 81.75, 82.67 and $77.79,78.85,80.90$ obtained at the same previous conditions.

- For germinated grains CV values were 25.23, 21.12, 19.11 and 27.23, $25.15,21.45$ for horizontal and vertical fan, respectively comparing to 49.71 for control treatment (manual broadcasting). These results were under fan peripheral speed of 1.7, 1.97 and $2.18 \mathrm{~m} / \mathrm{s}$ with $100 \mathrm{~mm}$ outlet path length. The highest values of C.U. are 74.77, 78.88, 80.89 and $72.77,74.85,78.55$ obtained at the same previous conditions.

- The specific energy at the suitable portable unit fan peripheral speed of $2.18 \mathrm{~m} / \mathrm{s}$ were 0.56 and $0.87 \mathrm{kWh} / \mathrm{fed}$, and accordingly the broadcasting costs were 10.60 and $13.85 \mathrm{LE} /$ fed for dry and germinated grains, respectively comparing to $20 \mathrm{LE} /$ fed for manual broadcasting. 


\section{REFERENCES}

Abo El-Naga, M. H. M (2006): Development of a distribution unit for sowing small grains by air stream. J. Agric. Sci. Mansoura Univ., 31(7): 143-158.

Alireza S. and M. J. Sheikhdavoodi (2012): Evaluating of Broadcasting Uniformity of Centrifugal and Oscillating Granular Broadcasters. Research Journal of Applied Sciences, Engineering and Technology 4(15): 2460-2468.

Coates, W. (1992): Performance evaluation of a pendulum spreader. Trans of The ASAE, 8 (3): 285-288.

Dragos, T. (1975): Farm machinery and equipment. Handbook. Ministry of Education. Bucharest, Romania. P. 272.

Gharekhani M.; M. Kashaninejad; A. Daraei Garmakhany and A. Ranjbari (2013): Physical and aerodynamic properties of paddy and white rice as a function of moisture content. Quality Assurance and Safety of Crops \& Foods 5 (3): 187-197

Gupta, R. K., Arora, G. and R. Sharma (2007): Aero dynamical properties of sunflower grain (Helianthus annuus L.). Journal of Food Engineering 79: 899-904.

Have, H. (1991). Planning and Control in Agricultural Field Mechanisation. Frederiksberg C, Denmark: The Royal Veterinary and Agricultural University. (C.F. Ismail, Z.E.1 and A.E. AbdelMageed, 2010)

Helmy, M. A., S. M. Gomaa; Sorour, H. M. and H. A. El Khateeb (2000): A compartive study of different planting methods for rice yield at Kafr El Sheikh region, Misr J. Ag. Eng, 17(2): 349- 361.

Hunt, R. D. (1983): Farm power and machinery management, Iowa State Univ. Press Ames, $8^{\text {th }}$ Ed. $28-29$.

Hunt, R. D. (1995). Farm Power and Machinery Management. Ames, Iowa: Iowa State University Press. (C.F. Ismail, Z.E.1 and A.E. Abdel-Mageed, 2010) 
Jha SN. (1999): Physical and hygroscopic properties of Makhana. J. Agric. Eng. Res., 72: 145-150.

Kamel, O. M; M. E. Badawy and H. A. El-Khateeb (2002): Evaluation performance of centrifugal fertilizer distribution from a twin-disc spreader. Misr J. Agric. Eng., 19 (3): 759-774.

Khoshtaghaza M. H. and R. Mehdizadeh (2006): Aerodynamic Properties of Wheat Kernel and Straw Materials. Tarbiat Modares University, P.O.Box: 14115-336, Tehran, Iran.

Kishta, A. M. and A. A. Eliwa (2005): Developed and performance evaluation of a local grain and fertilizer spreader. 13th Annual Conference of the Misr Society of Agric. Eng., 14-15.

Morad, M. M; M. A. Arnaot, H. A. El-Gendy and A. M. Farag (2005): Effect of some operating parameters on the performance of fertilizer broadcasting machine. Zagazig J. Agric. Res., 32 (4): 1327- 1347.

Nilsson, B. (1972). Optimering av maskinkapacitet vid spanmalsskord. Rapport nr. 11. Uppsala, Sweden: Institutionen for Arbetsmetodik och Teknik, Lantbrukshögskolan. (C.F. Ismail, Z.E.1 and A.E. Abdel-Mageed, 2010)

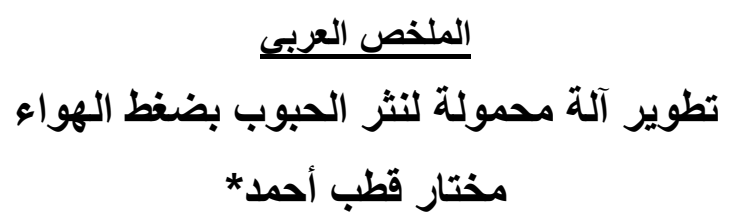

تعتبر عملية بذار الحبوب من العطليات الزر اعية المهمة بعد تهيئة مرقد مناسب للبذرة بعمليتي

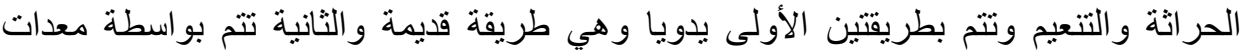

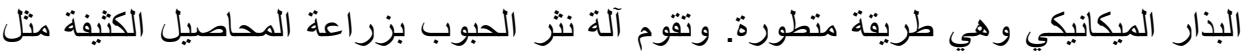

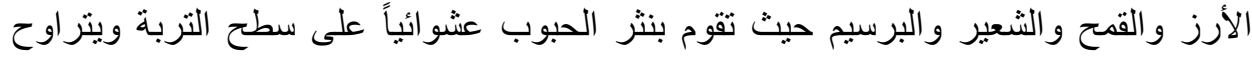

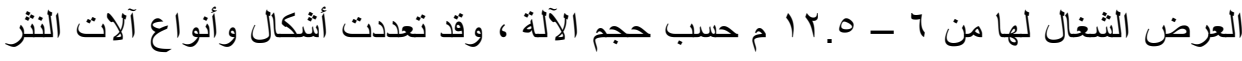

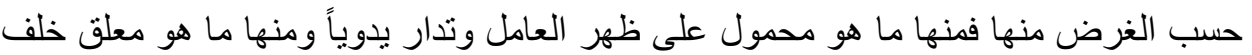
الجرار أو محمول على إطار خلف الجر ار أو النثر بالطائر ات.

*معهد بحوث الهندسة الزراعية - مركز البحوث الزراعية ـ مصر 
وتعتمد على وجود قرص تلقيم وريش عرضية تقوم بنثر الحبوب بالطرد المركزي مما يكسبها

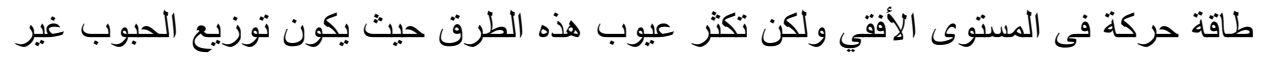

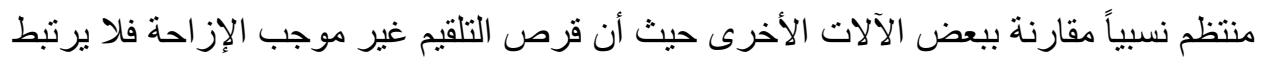

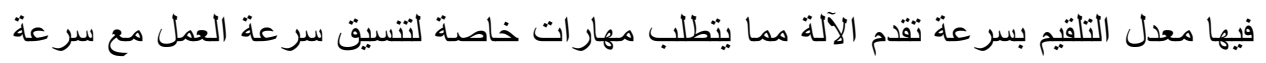

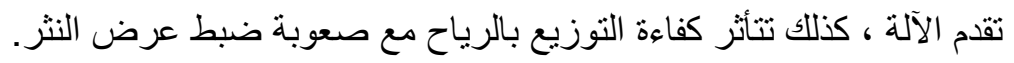

وللتغلب على هذه المشاكل أجريت هذه الدراسة حيث تم تطوير وحدة نثر محمولة على ظهر

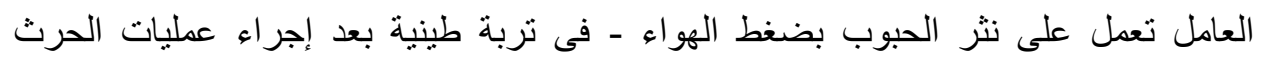

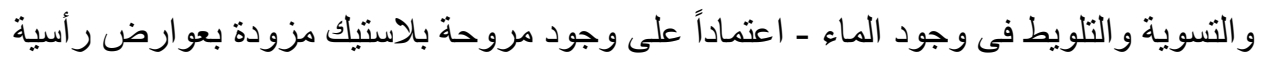

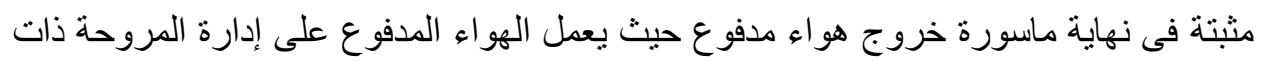

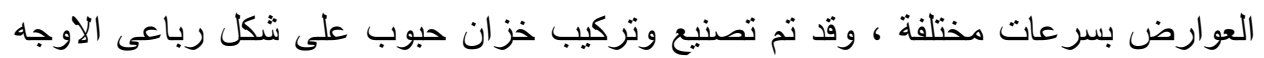

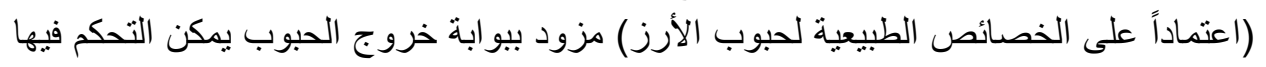

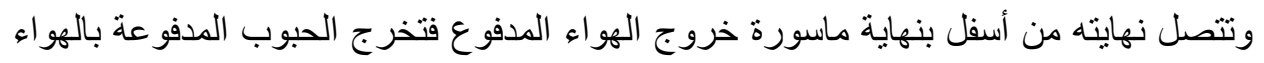

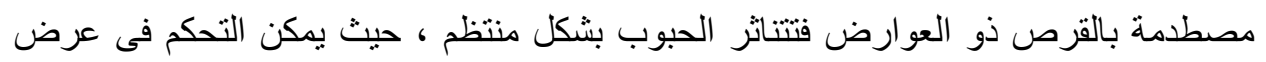

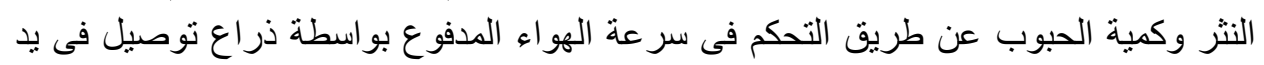

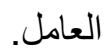

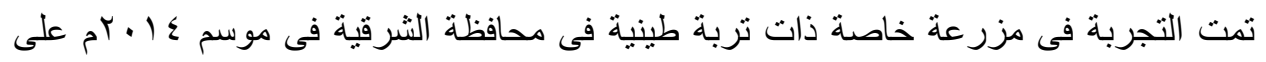

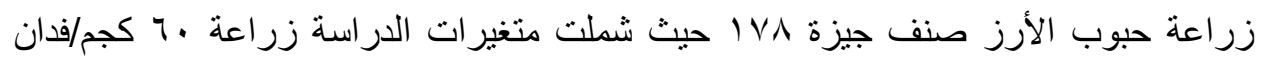

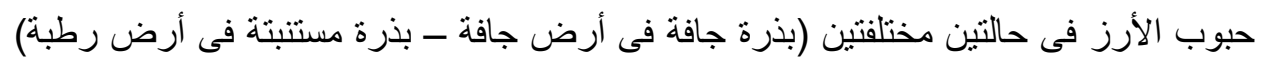

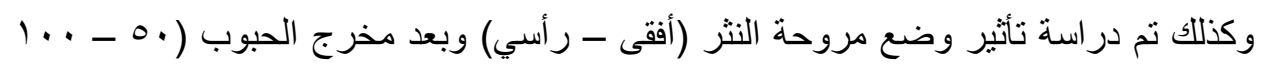

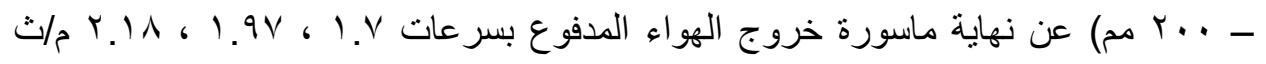

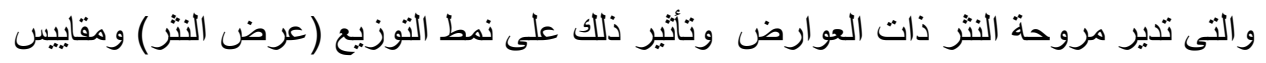
التشتت مثل معامل الانتظامية ، معامل الاختلاف ، وكذلك التأثير على التئ الطاقة المستهلكة و التكاليف الكلية.

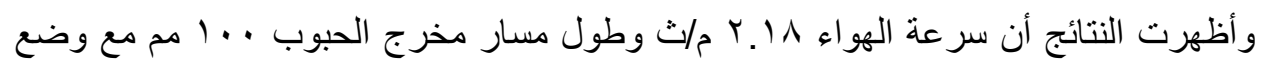

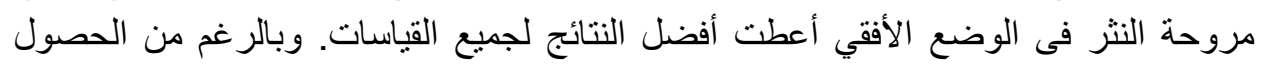

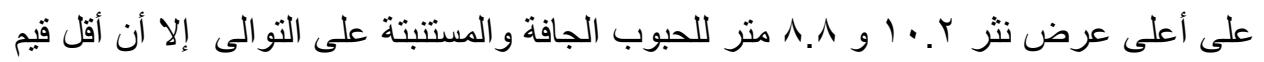

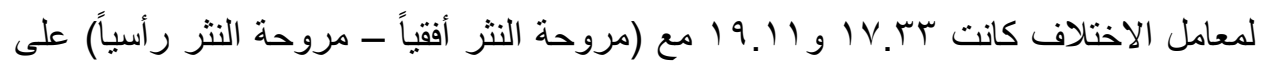

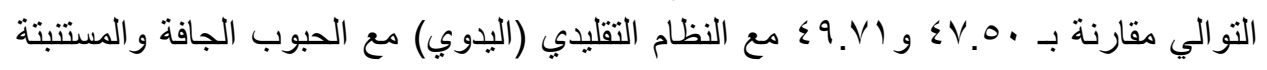

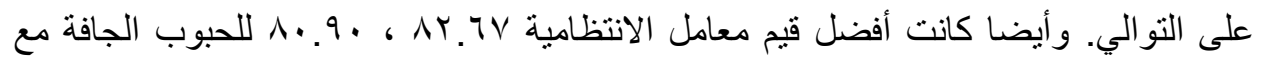

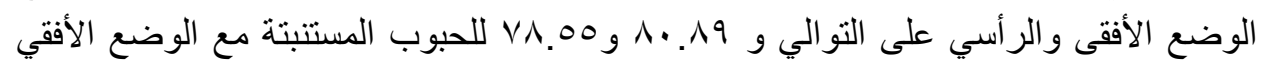

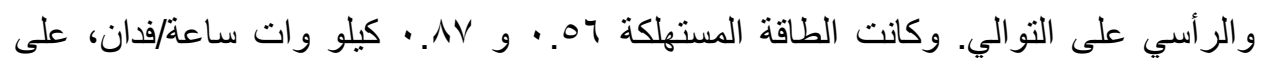




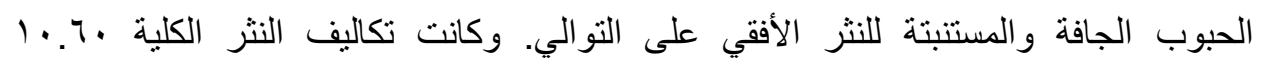

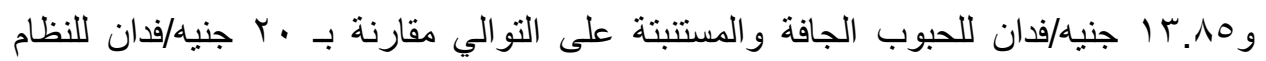
التقليدي.

وتوصى الدراسة بتصنيع آلة النثر المطورة للتغلب على المشكلات التى تواجهنا من تفتت

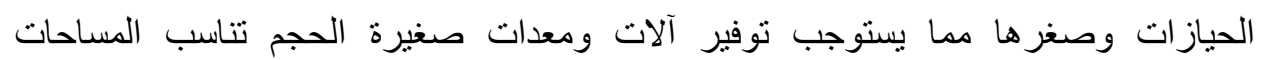

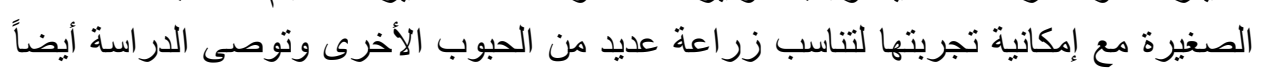

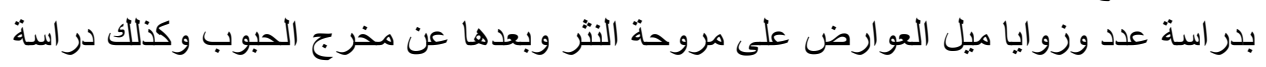

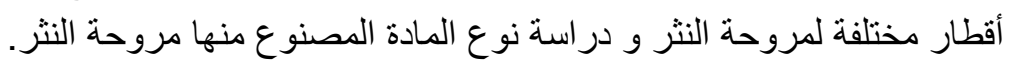

